\title{
Información, cibernética y biopolítica en la era de la globalización
}

Sebastián Alejandro Marín Agudelo

Universidad de Antioquia. Facultad de Comunicaciones y Filología. Escuela Interamericana de Bibliotecología |

sebastian.marin@udea.edu.co / https://orcid.org/oooo-00o2-7537-669X

\begin{abstract}
Resumen
Este artículo problematiza las relaciones que se entretejen entre información, cibernética y biopolítica en la actual era de la globalización y del poshumanismo. El trabajo aborda las formas de representación simbólicas de estas relaciones, de acuerdo con una concepción del mundo como sistema en el cual la información circula ahora globalmente. Se señala que la globalización de la información no solo es un instrumento de los mercados y del capitalismo sino que, además, determina las construcciones textuales, la gestación de las memorias y los discursos sobre los otros, gracias al empleo de las tecnologías y, específicamente, las del propio lenguaje.
\end{abstract}

\section{Information, cybernetics and biopolitics in the era of globalization}

\begin{abstract}
This article brings to attention the relationships that are interwoven between information, cybernetics and biopolitics in the current era of globalization and post-humanism, as well as the forms of symbolic representation of these relationships, according to a conception of the world as a system, in which the information now circulates globally, becoming not only an instrument of the markets and capitalism, but also, it determines some textualities, some memory and some discourses on others, thanks to the use of technologies and, especifically, those of the language.
\end{abstract}

Palabras clave

Información Cibernética Biopolítica Discurso Globalización

Keywords Information Cybernetics Biopolitics Discourse Globalization 


\section{Introducción ${ }^{1}$}

1. Artículo de revisión de literatura derivado del proyecto de especialización titulado “Temas, motivos y tópicos en el meme de Internet. Muerte y locura en Hamlet (1609), de W. Shakespeare, en Ofelia (1852), de Everett Millais y en el meme de Internet".
El pensamiento cibernético y el paradigma sistémico han permeado la forma en la que vivimos de maneras mucho más complejas de lo que parece. La vocación inicial de la transdisciplina cibernética, como se le ha denominado, permitió a otras ciencias y disciplinas, no sólo delinear su autonomía con respecto de otras, sino convertirse en núcleo fundamental de una visión del mundo moderno. La administración, la ciencia de la información, las ingenierías, la aeronáutica, la computación, entre otros campos y ramas, bebieron de este enfoque. Desde entonces, la tecnología se ha dirigido hacia la automatización de la producción y los servicios, de la gestión y de la ciencia, en términos de sistemas y de redes.

Este pensamiento también se ha representado a través de otros productos simbólicos como la literatura y, en general, las informaciones que registran hechos del pasado. No es para menos que en la actualidad se piense en toda una renovación teórica acerca de la función de la ciencia y de la relación hombre-máquina en medio de una multiplicidad de tensiones sociales, producto del crecimiento exponencial de la población mundial y su diversidad.

Algunos de los ejemplos más populares desde la literatura son Un mundo feliz de Huxley (1932), 1984 de Orwell (1948), Fahrenheit 451 de Bradbury (1958), publicada por primera vez en inglés, en 1953; y Sueños Digitales (2000) y El delirio de Turing (2003) de Edmundo Paz Soldán para el contexto latinoamericano, entre muchas otras obras. Los topos en esta literatura son siempre los medios, la información y la tecnología como formas para la consolidación de unas memorias y unos discursos sobre otros, incluso, unos cuerpos sobre otros.

Desde este punto de vista, la Web, y en general las Tecnologías de la Información y la Comunicación (TIC), vienen creando nuevas informaciones y, por tanto, textualidades que remiten a nuevos modos y formas de interactuar e interpretar el mundo, ahora a través de los medios y sistemas, que impactan sobre las relaciones de poder, en la medida en que determinan también los ritmos de trabajo y, en últimas, de producción, consumo y acceso, por medio de símbolos y discursos que se van haciendo globales con apoyo justamente del control de la información y de la tecnología.

Desde esta visión, la circulación inmediata de información a través de las nuevas tecnologías también viene moldeando las relaciones entre inclusión y exclusión social, hombre y máquina y, en general, entre vida y muerte, en tanto instrumento de control social, que es evidente en términos no sólo económicos, sino también lingüísticos y culturales.

\section{Método}

El texto compone el marco conceptual inicial del proyecto de investigación Temas, motivos y tópicos en el meme de Internet. Muerte y locura en Hamlet (1609), de W. Shakespeare, en Ofelia (1852), de Everett Millais y en el meme de Internet, que buscó rastrear las relaciones entre información, tecnología, memoria y discurso, a través del meme de Internet en el contexto de la globalización y la cibercultura. Los términos información, tecnología, discurso, memoria, globalización y cibercultura, entre otros, fueron las categorías para la búsqueda y selección de información en bases de datos como ScienceDirect, SciELO Colombia y Google Académico.

En tanto que el propósito era contar con un marco referencial inicial que apoyara la hipótesis del meme de Internet como registro de información sobre ideas, sensaciones y sentimientos que llevan consigo una serie de elementos de la cultura que representan 
y determinan, como lo hacen otras informaciones, memorias y discursos que circulan casi exclusivamente en el ciberespacio. Este rastreo se preguntó también por las relaciones entre cibernética, posthumanismo, biopolítica y biopoder. La búsqueda arrojó 215 resultados, de los cuales se seleccionaron 18 textos, de acuerdo a los criterios de pertinencia temática, para su posterior lectura, análisis e interpretación.

Desde esta óptica, la investigación utiliza la estrategia metodológica denominada "investigación documental", cuyo objeto de estudio es la investigación previa o los conocimientos acumulados desde un enfoque hermenéutico que, de acuerdo con Gadamer (1996), compone una doctrina de la comprensión de la realidad tal como los hombres la han producido.

Por lo tanto, este texto no es más que una interpretación basada también en lo que el investigador experimenta en el tiempo propio, ya que no es más un interlocutor entre la cuestión o la pregunta y las posibles respuestas.

\section{Del pensamiento cibernético a la biopolítica del poder y al posthumanismo}

En 1948 el matemático estadounidense Norbert Wiener, publica por primera vez su teoría Cibernética ${ }^{2}$ en el texto Cybernetics or Control and Communication in the Animal and the Machine (Cibernética o el control y comunicación en animales y máquinas), producto del auge del positivismo del siglo XIX y los desarrollos en el campo de la física y de la estadística. Esta teoría sentaría las bases para lo que posteriormente se convertiría en una metateoría de la ciencia: la Teoría General de Sistemas, expuesta por el biólogo Ludwig von Bertalanffy (1986), publicado originalmente en inglés, en 1968 , con un fuerte sustento en la física, la biología, la sociología y la administración.

El objetivo era estudiar los principios reguladores de los sistemas, y su premisa fundamental se basa en que puede entenderse el funcionamiento de cualquier sistema mediante el estudio de los mensajes y de las facilidades de comunicación de las que este dispone para su propio ajuste y mejoramiento. Este mismo principio se aplica, de acuerdo con Wiener (1985), a los mensajes cursados entre hombres y máquinas, entre máquinas y hombres, y entre máquina y máquina; es decir, una automatización en todos los sentidos.

También en 1948, el matemático, ingeniero eléctrico y criptógrafo estadounidense Claude Elwood Shannon, publica su texto A mathematical theory of communication, en el cual desarrolla ampliamente los conceptos de "Entropía" $y$ "Redundancia", e introduce el término bit, para designar la unidad más pequeña de información dentro de circuitos electrónicos, influyendo determinantemente en el desarrollo de los medios, las computadoras, las ciencias de la información y la inteligencia artificial. Este, a su vez es el mismo año en que el escritor George Orwell publica su famoso libro 1984.

En esta misma línea, los aportes de Vannevar Bush en 1945 influyeron profundamente en la visión de un sistema de pensamiento informático de enlaces y conexiones lógicas: el hipertexto, que sería la base para el nacimiento de Internet en la década de los 80 . Junto con el computador personal, la masificación de teléfonos móviles y de las redes sociales, la World Wide Web desarrollada por el informático teórico y físico BernersLee, compuesta en principio por un puñado de sitios web, textos, imágenes, audios, videos y otros contenidos virtuales multiplica para la primera década del siglo XXI, la información producida por la humanidad hasta entonces, creando con ello todo un nuevo mundo semántico, una sintaxis y una pragmática, que hoy conviven dentro de una semiótica informática o computacional, cuyo marco de expresión son los códigos informáticos y lenguajes de programación.

De la voz griega kybernetes, traducida como timonel o gobierno, con lo que la comunicación es asociada con las nociones de control, regulación y dominio (Breton, 2000). 
3. (1516). Título original Libellus vere aureus nec minus salutaris quam festivus de optimo reipublicae statu, deque nova insula Utopia. Traducción en español: Librillo verdaderamente dorado, no menos beneficioso que entretenido, sobre el mejor estado de una república y sobre la nueva isla de Utopía.
Esta reflexión no es nueva para pensadores y filósofos, ya muchos han señalado que el hombre ha perdido su autonomía en todo este entramado y está ahora adiestrado o condicionado por la tecnología, producto de una mecanización progresiva: el individuo se convierte cada vez más en un engranaje de un sistema mayor. Para Von Werder (2020) en Mundos y seres poshumanos en la literatura contemporánea, esta idea de un individuo que forma parte de un conjunto imbricado de sistemas y elementos que lo anteceden y lo sobrepasan debido a que se instauran como representación del sistema mismo, y que en la actualidad hace referencia al término posthumanismo, había sido formulada también por autores como Foucault o Lacan, hace algunas décadas, para referirse a las estructuras de poder y otros factores, como los psicológicos, o los relacionados con la salud pública y el control de las poblaciones, entre otros, que de una, $u$ otra manera, normalizan o estructuran un sistema de pensamiento; o, dicho de otra manera, determinan la autopercepción individual y colectiva de los sujetos políticos respecto a un sistema social.

La discusión subyace en si este pensamiento es un modelo aplicable a los gobiernos y a la sociedad en su totalidad, independiente de la idea de vincular los cuerpos con las instituciones como espacios físicos. "Este punto de vista teórico ofrece una importante conexión con la realidad de la era de las redes y la irrupción del mundo del e-gobierno." (Szlejcher, 2008: 96). Desde la literatura, por ejemplo, la idea de "una organización social en la que se contenían las suficientes cautelas para conseguir que la sociedad diseñada careciese de aspectos indeseables, que en su funcionamiento se evitara la injusticia, la explotación, el abuso y la desigualdad" (González Quirós, 1981: 1), sobreviene de la idea de utopía, recordando a Tomás Moro y su Utopía ${ }^{3}$, en la que existen unos modelos ideales de Estado y de sociedad.

La historia de estas propuestas utópicas, de acuerdo con González Quirós (1981), nos enseña un diverso abanico de posibilidades en las que, una vez alcanzada la nueva estructura social, la pacificación de la existencia y la felicidad individual quedaban garantizadas. No obstante, esta visión tiene su contraposición o su versión negativa. En la Utopía Negativa se nos describen las consecuencias de la búsqueda de esa perfección como formas de un pensamiento antiutópico. La diferencia está en que estas suponen una crítica, no ya de la sociedad ahora establecida, sino de la vida humana previsible en un futuro en el que aparentemente existe una perfección social.

Algunos ejemplos son The Iron Heel, de Jack London (1908), Nosotros (о Mы, en ruso) de E. Zamiatin (1991), publicado por primera vez en ruso, en 1924, y las ya mencionadas Un mundo feliz de Huxley (1932), 1984 de Orwell (1948), Fahrenheit 451 de Bradbury (1953); y Sueños Digitales (2000) y El delirio de Turing (2003) de Edmundo Paz Soldán para el contexto latinoamericano, e Iménez (2011), de Luis Noriega, entre otros, para el caso colombiano.

Para Saldías Rossel (2015) se trata de un fenómeno, el impulso utópico, como una característica funcional, central e inspiradora de los productos culturales literarios distópicos. Estas narraciones tienen como topos literarios los medios de producción, la información y la tecnología, como una forma para consolidar unas memorias y unos discursos sobre otros, incluso, unos cuerpos sobre otros. Para Brunori (2012) estamos viviendo una era de controversiales revoluciones biomédicas, en la que se ponen en discusión los efectos que estos progresos pueden tener sobre la raza humana, y se empieza a hablar del hombre "posthumano", que significa en palabras de Brunori:

(...) la superación de lo meramente humano, que es desplazado como modo dominante de vida; engendra la hibridez, la heterogeneidad y la multiplicidad; por ende, la visión antropocéntrica y el sujeto son descentralizados. De este modo, el ideal humanista del sujeto liberal, racional y autónomo se ve, para 
muchos, amenazado. Sin embargo, los transhumanistas [...] también promueven la aplicación directa de la medicina y la tecnología para la superación de ciertos límites biológicos (Brunori, 2012: 25).

Mientras que, de acuerdo con Brunori (2012) y Haraway (1991), para los transhumanistas no hay diferencia moral entre el perfeccionamiento humano a través de la tecnología y otras formas de progreso, y remiten a una nueva forma de ser humano en un mundo hiperconectado, es decir una nueva etapa de la línea evolutiva, no del hombre sino de la naturaleza misma; para otros lo posthumano es necesariamente deshumanizador en tanto "no hay diferencias esenciales o demarcaciones absolutas entre la existencia corporal y la simulación computada, el mecanismo cibernético y el organismo biológico, la tecnología robótica y los objetivos humanos" (Hayles, 1999: 3).

Los peligros de esta tendencia, no obstante, ya los había señalado el mismo Bertalanffy, en la introducción de su Teoría General de los Sistemas; para él, al nuevo mundo cibernético no le importa la gente sino los "sistemas"; el hombre se vuelve reemplazable y gastable, precisamente es el "elemento humano" el componente inconfiable de sus creaciones, por lo que, o bien se elimina del todo sustituyéndolo por el hardware de computadoras o maquinaria autorregulada, o bien hay que hacerlo tan confiable como se pueda: mecanizado, conformista, controlado y estandarizado (Bertalanffy, 1986).

Lo anterior se relaciona también con las premisas del filósofo Foucault (2004) en su teoría sobre el nacimiento de la biopolítica y el biopoder, en el que la individualización del humano sirve para bloquearlo y suprimirlo de su propia subjetividad y su corporeidad, al normalizarlo, uniformarlo y disciplinarlo como individuo anómico y como masa medible y cuantificable (Tejeda González, 2011). La cárcel, el hospital, la empresa y las escuelas reproducen de una u otra forma los imperativos sistémicos de la normalización del sujeto y los cuerpos, por lo que las concepciones que estas instituciones, así como los sujetos, tengan de cultura, arte, ciencia y tecnología, determinan el entramado de relaciones de poder y los paradigmas dominantes. Es así como la noción de progreso científico y tecnológico como progreso en sí se ha impuesto a lo largo del siglo XX y ha provocado hoy una desconfianza igualmente fuerte acerca de estas mismas tecnologías, en la medida en que estas han servido para reemplazar, controlar, vigilar y limitar al hombre.

No obstante, para Silva Silva (2008), el uso de las TIC y la intensa puesta en "red" de los actores y gobiernos territoriales "aparece como una palanca muy interesante para desarrollar, a mayor escala, una práctica de 'ciudadanía activa' y una dinámica de desarrollo local en territorio concreto". En esa medida, Internet, en la actualidad, es mucho más que una tecnología, es un medio de comunicación, de interacción y de organización social. Se puede constatar lo expuesto anteriormente, toda vez que Internet expresa los procesos, los intereses, los valores y las instituciones sociales.

Desde la óptica de la biopolítica de Foucault, los mecanismos de control y vigilancia pueden ser tan comunes que no los notamos, los datos, por ejemplo, sobre el acceso a información y bienes de consumo podrían servir para el control demográfico y la administración de las poblaciones, central en la conexión entre la vida, la política y el poder. Para Ortiz Palacios (2016) ya no se trata de relación cuerpo-máquina sino "cuerpo-extendido" sobre y desde el cual se "corrige" ahora, también, su información celular, molecular, genética. El imperativo de la salud, por ejemplo, tiene entre sus objetivos aumentar la fuerza física, las aptitudes y la vida en general. De ahí que se gestione la natalidad, la mortalidad, la longevidad, utilizando ahora las nuevas tecnologías y los datos, producto de estas interacciones. En ese sentido, "el hombre existente ahora se reconoce en las nuevas relaciones de composición con el silicio y no 
4. Esta idea de progreso también ha sido formulada por Norbert Elias (2016) en su texto El proceso de la civilización. Investigaciones sociogenéticas y sicogenéticas, publicado por primera vez en 1939; como concepto, el progreso plantea una ideología esencial en la definición de la llamada sociedad de la información (Becerra, 2003) y, más ampliamente, en la definición de los imaginarios colectivos sobre las tecnologías de la información y la comunicación y sus impactos en la sociedad y la cultura (Wolton, 2000). únicamente con el carbono. Ya no se indicará ni el orden general, ni la comparación infinita, sino la diversidad ilimitada de combinaciones" (Ortiz Palacios, 2016: 219).

Este control se da, para Tejeda González (2011), de forma directa sobre la evolución de las poblaciones, las tasas de natalidad y de mortalidad, así como de los fenómenos migratorios. Las formas de biopolítica y biopoder que observamos giran, en todo caso, en torno al concepto de sistema: los sistemas de gobierno, los sistemas de información, la lengua como sistema, el "sistema literario", entre otros.

Es por eso por lo que la información, de acuerdo con Siles González (2007), detenta en todo esto, un rol como principio de orden con relación al caos que plantea la "entropía social", en este sentido, su rol principal dentro de todos los sistemas es el mejoramiento del control y progreso del "sistema social". 4 La información es, desde esta perspectiva, el núcleo central del proceso de ajuste por parte del sistema y de la aplicación de los resultados de esa adaptación.

\section{Nuevos documentos, nuevos textos y discursos}

Todos los días se publican en Internet miles de imágenes, textos, videos, animaciones y audios, entre otros, con muy variados y diversos objetivos académicos, investigativos e independientes que, como lo señala Martín-Barbero, sirven a la vez de espacio estratégico de creación y apropiación cultural, "y de activación de la competencia y la experiencia creativa de la gente, y de reconocimiento de las diferencias, es decir de lo que culturalmente son y hacen los otros, las otras clases, las etnias, los otros pueblos, las otras generaciones." (Martín-Barbero, 2002: 223). La Web compone entonces un megasistema mnemotécnico, no sólo en el sentido utópico borgiano, sino, además, en la perspectiva de Vannevar Bush (para muchos el padre del hipertexto), cuando en 1945 en su ensayo "As We May Think" menciona:

Veremos aparecer formas totalmente nuevas de enciclopedias, conteniendo de origen numerosos senderos de información preestablecidos, listas para ser introducidas en el memex con la capacidad de ser ampliadas por el usuario. Así, el abogado tendrá a su alcance las opiniones y decisiones de toda su carrera, así como las de la experiencia de sus amigos y de las autoridades en la materia. El jurista de marcas y patentes tendrá a su disposición toda la información relativa a millones de patentes, en la cual ya ha creado los familiares senderos que resulten del interés de sus clientes. El médico, confundido por la reacción de un paciente, accederá a los senderos que creó al estudiar un caso parecido [recordemos la medicina actual basada en la evidencia], y recorrerá rápidamente el archivo de los historiales de casos clínicos análogos, así como las referencias cruzadas a los clásicos de la anatomía y la histología. El químico, lidiando con la síntesis de un compuesto orgánico tiene a su disposición toda la literatura química dentro de su propio laboratorio, con senderos de información que siguen las analogías entre distintos compuestos, así como senderos bifurcados que dan cuenta de su comportamiento físico y químico. (Bush, 1945: 12-13).

Las formas, soportes y objetivos del control y la acumulación de información y medios electrónicos y digitales están presentando características tan específicas, y a la vez tan inestables, que obligatoriamente están creando nuevas experiencias en los productores y consumidores o usuarios de la información. Estas nuevas formas de acceso y uso de la información están siendo interiorizados en forma de "habitus", de ahí "[...] las distintas consideraciones del homo digitalis" del documentalista López Yepes (1998) o del homo videns de la Sociedad teledirigida de Sartori (1998). 
En ese orden de ideas, a la vez que los libros, los documentos de archivo, las fotografías, los videos, entre otros, se han venido digitalizando, se van creando nuevas formas de registro sin que haya existido un proceso previo de transformación de un medio a otro, con los mismos fines de los primeros: informar, comunicar, dar fe, registrar un hecho relevante o expresar un sentimiento o una idea. Entre estas nuevas formas de registro podemos referenciar especialmente los memes ${ }^{5}$, los tweets, los gifs, entre otros formatos de información digitales que están siendo también testimonios de muchos aspectos de la vida humana, entre otros, de sus formas de leer, escribir y crear contenidos.

Para Urbina Blanco (2020), es indudable que estamos dentro de un pluriverso de muchos contextos que nos llegan como novedosos, pero más aún, como fenómenos que siempre surgen como consecuencia de grandes cambios. Particularmente, cultura y globalización, revisten también de un nuevo sentido la idea de la identidad, ahora múltiple y plural.

El texto es ahora hipertexto. La página es ahora pantalla. El yo es ahora una multiplicidad de espejos y de ventanas al ser, incluyendo el segundo yo del ciberespacio. La cultura ya no se reduce a su propia evolución como multiculturalidad, transculturización o interculturalidad (Urbina Blanco, 2020).

De ese modo, concebir la sociedad se nos torna muchas veces como códigos entre textos, una intertextualidad que mantiene la relación entre referentes, que se vinculan explícita o implícitamente con un contexto, que influye tanto en la producción como en la comprensión del discurso (Urbina Blanco, 2020). Estos textos confluyen para crear una dimensión alternativa pero próxima a nuestra frágil "realidad" a través de distintos y variados textos, códigos o símbolos. La Internet, los memes, los hipertextos (es decir las páginas y servicios web) favorecen, en esa medida, la conformación de una hiperculturalidad cuya base son ahora las interrelaciones.

En esa medida, tanto los memes, como otras formas de información que la sociedad digital trae consigo, son fuente de información sobre los modos de reflexionar e interpretar una parte del mundo, en tanto posibilitan un conjunto de prácticas normalizadas que sirven para la transmisión cultural. Para Urbina Blanco (2020) particularmente los memes pueden ser convertidos en armas psicopolíticas para el control voluntario y consensuado de las masas, en tanto suerte de "invariable cultural", al "dominar" o concentrar el universo de informaciones que circulan en la red, especialmente en las redes sociales (RRSS), y no hay mejor simulación de la realidad social actual que las redes sociales.

Para Sartori el "nuevo soberano es ahora el ordenador [...] (y con él la digitalización de todos los medios) no sólo unifica la palabra, el sonido y las imágenes, sino que además introduce en los 'visibles' realidades simuladas, realidades virtuales" (Sartori, 1998: 32). Aunque para este autor las posibilidades de lo real se amplían enormemente, se trata únicamente de simulaciones consecuencia de la "carretera de información", ahogada y embotellada en un tráfico de informaciones del que el transeúnte no es consciente, pero que determina lo que le es visible.

El paradigma tecnológico y globalizado que rebasa y determina al hombre contemporáneo, nos remite a la metáfora del Cyborg, indómito y poderoso, pero frágil, vulnerable y ansioso si se le despoja de "sus tecnologías". Esta ansiedad se da, de acuerdo con Villegas Iriarte y Rueda Ortíz (2017), porque las tecnologías le garantizan el acceso al sistema mnemotécnico global, del que el archivo de su propia vida hace parte, es decir, le garantiza el acceso, al menos en parte, al sistema colectivo de enunciados, un "archivo infinito", a la forma de Borges y otros autores como Melo Flórez (2011) y Turkel (2005-08) (Figura 1).
5. Cuando se habla del meme en Internet como objeto de estudio, usualmente se hace referencia al trabajo de Richard Dawkins, El gen egoísta publicado en 1976 En el que el autor plantea los primeros debates de lo que hoy conocemos como memética. En este estudio Dawkins planteó los mecanismos de transmisión cultural y llega a la idea de una unidad de sentido cultural. 


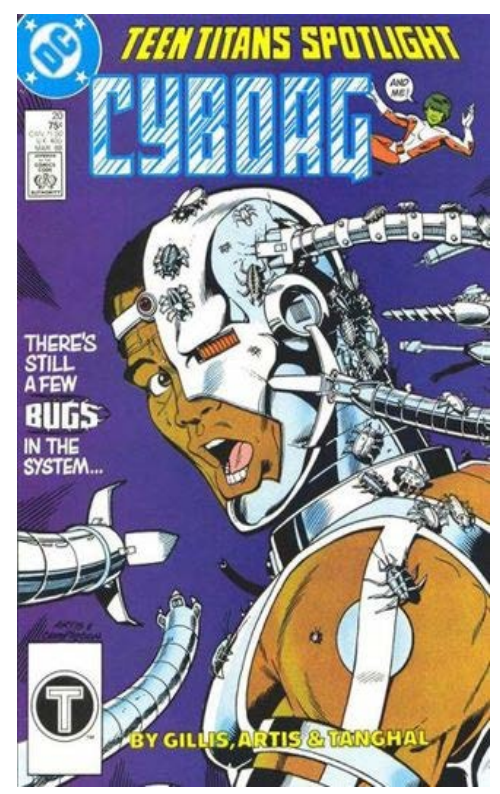

Figura 1. Giornado, D. (1988). Teen Titans Spotlight. Vol 1, no. 20. Portada: Tom Artis.

La colección y conservación, por su parte, de libros, cartas, títulos, volantes, facturas, fotografías o cualquier otro objeto con un código inscrito que pueda ser decodificado e interpretado, y que pueda servir como evidencia de que actuamos y pensamos, está, para Derrida (1995) en su Mal de archivo, en el orden de lo natural, pues aunque podamos manipular este instinto y priorizar unas memorias sobre otras, así como los discursos inmersos en estas, nuestra sola voluntad no podría contener la producción de registros, igual que de discursos, aunque se creen con el objetivo de emplazar unos sobre otros, unas memorias sobre otras. A propósito, el escritor George Orwell (1948), en su novela distópica, 1984, anotaba que:

Estaban los enormes depósitos donde se almacenaban los documentos corregidos y los hornos ocultos donde se destruían los ejemplares originales. $Y$ en algún lugar, de manera casi anónima, estaban los cerebros que coordinaban todo el trabajo y bosquejaban la política que hacía necesario que se preservara un fragmento del pasado, se falsificara otro y se borrara un tercero de la existencia (p. 51).

La información registrada además de ser “[...] un invento que lleva a cabo el ser humano a fin de poder conservar las ideas, las sensaciones, los sentimientos más allá de su memoria, más allá de sí mismo facilitando al mismo tiempo la capacidad de transmisión de los mismos" (López Yepes, 2008: 276), es un vehículo que sirve para transmitir unas memorias y unos discursos, a través de su registro, en tanto producción del intelecto humano y práctica social del hombre. De modo esquemático, según López Yepes (2008) podemos indicar una serie de características que se inscriben dentro de esta perspectiva de la información registrada:

»El documento como técnica de prolongación del ser humano.

» Tendencia humana al registro, transmisión y conservación de ideas, sensaciones, sentimientos y datos.

» Objetivación en soportes físicos.

»Elementos para el gobierno y administración de las comunidades. 
En ese sentido y de acuerdo con Morales Campos (2007), la diversidad de la información que se genera y que usamos expresa la diferencia de interpretaciones entre culturas, por lo que es preciso reconocer una infodiversidad, en tanto representa el conjunto de ideas, sensaciones y conocimientos registrados, que le permiten al hombre su accionar en el mundo como sujeto político y simbólico. "Hablar de infodiversidad es reconocer las diferencias de contenido y de estilo, de formato y de procedencia, de lo efímero y lo permanente, de lo académico y lo popular, de lo demandado por el gran público y por el especializado, por las mayorías y las minorías que forman nuestros espacios vitales." (Morales Campos, 2007: 60).

\section{Información, biopolítica y globalización}

El desarrollo tecnológico al que hemos referido, en cuanto a los medios de comunicación electrónicos para la transmisión de datos, viene imponiendo un éxodo de las tareas que se realizaban de forma completamente manual hacia nuevos entornos: el electrónico y el digital. Es así como la movilización y combinación de los recursos y las herramientas de información se han venido transformando, incluso con objetivos muy concretos y específicos: sistemas de información geográficos, ambientales, oceanográficos, entre otros.

Estos sistemas proveen datos que, combinados con los generados en el ámbito de la salud, por ejemplo, sobre pacientes, enfermedades, tratamientos, medicación y resultados, vienen convirtiéndose en piedra angular de los planes de acción de hospitales y médicos. Nuestro cuerpo se ha convertido en una fuente más de datos: radiografías, mamografías, tomografías computadas (TACs), resonancias magnéticas (Pulido Cañabate, 2016). El almacenamiento y análisis de todos estos datos juega un papel fundamental en lo que, según expertos será la medicina del futuro o medicina " $4 \mathrm{P}$ ": personalizada, predictiva, preventiva y participativa, que empieza a ser cada vez más evidente con la actual pandemia originada por el Covid-19 (Figura 2).

Para Ortiz Palacios (2016) al poderse identificar, aislar, almacenar y recombinar las informaciones sobre las intervenciones e investigaciones de tipo biológico y tecnológico, se espera ahora la predicción sobre los posibles efectos sobre la vida de manera anticipada, por lo que nos encontramos frente a nuevos modos de "normalización mediática" o "normalización informacional". Los datos, último eslabón en la escala del conocimiento, se posicionan en la biopolítica moderna, a través de cuatro ejes: el primero, la predicción estadística; el segundo, las nuevas teorías de los mass-media, con especial énfasis en los dispositivos móviles y portables; el tercero, las nuevas materialidades y soportes de la información, que empareja hombres, animales y máquinas; el cuarto, la desaparición de lo público y lo privado (Ortiz Palacios, 2016), en el que es difícil el control de movimientos de la información, entre estas dos esferas de la vida.

Este nuevo tipo de control, basado en la información útil para la toma de decisiones, permea todas las esferas que afectan al hombre, los gobiernos, la ciencia y la tecnología, la cultura y, en general, en todos los sectores económicos. Esto es lo que Marshall McLuhan denominó como "Aldea Global", término acuñado en su obra a finales de los sesenta, y que servirá de sustento para que Theodore Levitt acuñe el término "Globalización" en 1983, al poner en contexto global las dinámicas del mercado, desde la expansión de los medios de comunicación, de la información y de la población. 


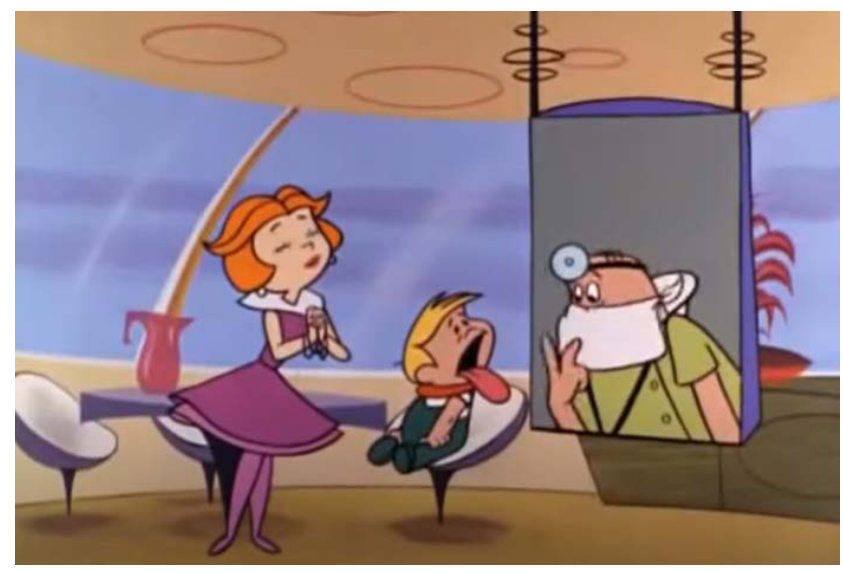

Figura 2. Hanna, W. y J. Barbera (1962-1987). Supersónicos (título original The Jetsons). Estados Unidos: American Broadcasting Company ( $\mathrm{ABC})$. Fotograma.

Como concepto, Globalización, toma una mayor preponderancia en los años noventa gracias a la instantaneidad y articulación de la información que flota libre de sus transportadores en el ciberespacio, sin importar la traslación y el posicionamiento de los cuerpos en el espacio físico como bien lo señala Bauman (2017). Los cuerpos son, desde esta perspectiva, prescindibles para el reordenamiento de significados y para las relaciones de poder, pues los negocios y las grandes decisiones se administran y se toman ahora a distancia. Bauman en su texto La globalización. Consecuencias humanas, publicado por primera vez en inglés, en 1998, menciona que esta globalización divide en la misma medida que une y las causas de esta división:

"[...] son las mismas que promueven la uniformidad del globo. Juntamente con las dimensiones planetarias emergentes de los negocios, las finanzas, el comercio y el flujo de información, se pone en marcha un proceso "localizador", de fijación del espacio. Estos dos procesos estrechamente interconectados introducen una tajante línea divisoria entre las condiciones de existencia de poblaciones enteras, por un lado, y los diversos segmentos de cada una de ellas, por otro. Lo que para algunos aparece como globalización es localización para otros; lo que para algunos es la señal de una nueva libertad cae sobre muchos como un hado cruel e inesperado. La movilidad asciende al primer lugar entre los valores codiciados; la libertad de movimientos, una mercancía siempre escasa y distribuida de manera desigual, se convierte rápidamente en el factor de estratificación de nuestra época moderna tardía o posmoderna." (Bauman, 2017: 8).

El desarrollo de más y mejores medios de transporte y rutas de comunicación terrestres, marítimas y aéreas, ha generado en la actualidad uno de los mayores desplazamientos y movimientos de personas alrededor del globo, creando, al mismo tiempo, el encuentro de diversidad de lenguas y culturas que, nos guste o no, por acción u omisión, todos estamos viviendo, aunque físicamente permanezcamos en reposo. Los efectos de la nueva condición son drásticamente desiguales, mientras algunos se vuelven plena y verdaderamente globales, otros quedan detenidos en su "localidad", un limbo en un mundo en el que los "globales" imponen las reglas del juego (Bauman, 2017).

Lo anterior resulta evidente en relación con la crisis del vínculo entre cultura y territorio, provocada por la interconectividad planetaria y las distintas formas culturales que vienen entrando en contacto, generando mestizaje e hibridación cultural. Además de la expansión de los mercados, podemos observar grandes migraciones en todo el 
globo, que promueven la progresiva eliminación de las barreras que antes regulaban la circulación de productos y servicios en países, regiones y localidades (Juanola Hospital, 2004). Los efectos, entonces, de esta Globalización que fomenta el encuentro y el acceso a la información, los bienes y servicios, impone no sólo en términos económicos, políticos o sociales, sino también lingüísticos y culturales, una homogeneización de las lenguas y las culturas. ${ }^{6}$ La razón de esto, de acuerdo con Juanola Hospital (2004), es que la noción de cultura ayuda a configurar una mirada al mundo en términos globales que cumple un importante papel de mantenimiento de una serie de relaciones favorables a los mercados, en cuanto a la distribución de productos, información y servicios.

La idea de un mundo homogéneo culturalmente, en consonancia con los intereses del capitalismo, puede verse mayormente reflejada en la lengua y cultura global. El inglés, que en la actualidad viene ejerciendo fuerza sobre las demás lenguas super-centrales, centrales y periféricas, dando paso no sólo a colonialismos culturales y lingüísticos, sino además, contribuyendo a la agudización del riesgo de pérdida de lenguas en el mundo y, a cierto capitalismo cognitivo que, como lo menciona Hidalgo Rivero (2014), determina también la producción de conocimiento, como elemento indispensable para el crecimiento y la competitividad de los mercados. A lo que Ortiz (2009) añade:

Cuando vemos la expansión de las bases de datos, la constitución de los bancos de informaciones, libros, artículos, citas y-con el advenimiento de Internet-revistas on line, todo conjugado de manera prioritaria en inglés, tenemos la falsa impresión de que tamaño abarcamiento es señal de universalidad. Publicar y ser citado en inglés no sería el resultado de la expansión de un circuito, de su ampliación territorial, sino la condición primera del pensamiento (de allí que los autores anglonorteamericanos se hayan adaptado tan bien al monolingüismo; después de todo, casi no existiría relevancia científica fuera de su égida). Escribir en otra lengua ya no significa estar circunscripto a una determinada forma de expresión; dicha condición se percibe como un localismo, una limitación. (Ortiz, 2009: 50).

Se trata de una mercantilización de las expresiones humanas, basada en la virtualización y cuyo funcionamiento depende de las variadas tecnologías de comunicación lingüísticas, entre las cuales se encuentran los motores de traducción, que permiten una difusión inmediata de información entre distintas lenguas. De ahí, que los motores de traducción al traspasar las barreras del idioma y poner el conocimiento rápidamente al alcance, al menos desde el punto de vista lingüístico, se hayan tornado en una herramienta indispensable en el proceso de aceleración del uso y la mercantilización no sólo del conocimiento, sino, en general, de los productos y servicios que los mercados promueven, en tanto se garantiza la rapidez de las reacciones y la adaptabilidad ante las innovaciones (Hidalgo Rivero, 2014).

Se entiende, en consecuencia, que, para la difusión y mercantilización prontas del conocimiento, es necesario el empleo de tecnologías lingüísticas que superen las brechas que demanda el intentar comunicarse en distintos idiomas. Lo anterior no sería un problema si la exclusión de lenguas y, por tanto, de los sistemas de signos lingüísticos en interacción, no fuera también la exclusión de las visiones y relaciones de los pueblos, especialmente indígenas, con el mundo y la naturaleza. De allí se derivan conocimientos específicos, cosmogonías, modos de producción y formas de vida únicas, que contribuyen también a la ciencia del clima, a la biodiversidad y a la sostenibilidad, por ejemplo.

De ese modo, elementos culturales, como las cosmogonías y visiones de la naturaleza, son subsumidas por aquellas cosmogonías y visiones de las lenguas y culturas globales, que determinan al mismo tiempo, el acceso a la información y, por tanto,
6. Lengua y cultura, es el "binomio indisociable que da a los individuos su sentimiento de pertenencia identitaria" (Simón Ruiz, 2010: 76). 
al conocimiento. No se trata de un problema menor, del éxito en la coexistencia de las lenguas y culturas depende el intercambio de saberes, conocimientos, prácticas y costumbres y, por tanto, el mejoramiento de las condiciones de vida de las poblaciones, en tanto se trata de una competencia comunicativa, que desde la perspectiva cibernética determina las posibilidades de progreso.

La difusión de los descubrimientos científicos, por ejemplo, a través de las nuevas tecnologías, se da mayoritariamente en inglés, obligando a las poblaciones y localidades a repensar los contenidos y las estrategias de transmisión de los saberes, y al mismo tiempo, a adecuar los esquemas cognitivos a las diferentes rutas de comunicación que se ofrecen para compartir el conocimiento, dado que Internet permite ahora, en los lugares y comunidades, con más recursos, el acceso a bibliotecas, centros de documentación $\mathrm{y}$ a bases de datos sin necesidad de que el usuario se traslade a ningún lugar y sin su presencia física. Cosa que se traduce no solo en el acceso a información, sino, además, a productos culturales y simbólicos como literaturas y arte, lo cual para Morales Campos (2007), compone también un elemento fundamental en cuanto a las migraciones:

Las migraciones se tienen que entender no sólo como un desplazamiento físico de grupos sociales, es necesario dimensionar la influencia que llegó a través de la educación, la ciencia, el arte y la cultura en general, que no necesariamente se enriqueció con la presencia de personas, sino a través de libros. Además, habría que agregar que tal aportación cultural es de ida y vuelta, pues llegaron migrantes a estas tierras, pero también los locales fueron a conocer ciudades de otras latitudes. La información producida por los migrantes y los locales también fluyó, se movilizó y desplazó en varias direcciones. Por lo que, hoy en día, este intercambio transfronterizo de elementos culturales se ha establecido en el terreno de la información y de los datos, así como en el comercio y el flujo de impresos y de información que se ha incrementado exponencialmente con las nuevas tecnologías de información y con herramientas como el Internet y las páginas Web. (Morales Campos, 2007: 58).

Para Tejeda González (2011), la política demográfica, migratoria y de las poblaciones, así como aquella que determine la circulación de conocimientos es a todas luces un ejercicio de biopolítica. La biopolítica, en este sentido, entra en nuestras vidas como organización y administración de la calidad de vida. Son las políticas poblacional e informacional, los componentes más visibles de lo biopolítico, aunque se extiende a las políticas sanitarias, sexuales, reproductivas y del tiempo libre, a través de los medios de producción y comunicación, así como de las tecnologías.

\section{Notas finales}

Como en otros momentos de la historia, la utilización de la tecnología, tanto en la vida cotidiana de las personas como en las instituciones, ha estado restringida sólo a algunos pocos; hoy, sin embargo, vemos que Internet ha revolucionado el acceso a la información de todo tipo, estrechando muchas fronteras evidentes como las geográficas, por ejemplo. No obstante existen limitaciones que impactan en la recepción de ciertos contenidos simbólicos y culturales, que promueven un desarrollo o un adormecimiento cultural en diferentes contextos sociales causado, entre otras cosas, por la sobreabundancia de información del ciberespacio. Estas limitaciones son de orden económico, lingüístico, educativo, etc.

Sin duda, la información y los discursos circulan ahora en mayor medida en las redes sociales, por lo que se trivializan, de acuerdo con comunidades específicas que normalizan unos discursos y los tornan ordinarios, sin otra función que entretener 
y divertir, del mismo modo que otras comunidades, normalizan otros discursos, con otros objetivos y funciones más que el mero entretenimiento. Eso, sumado a la posibilidad de crear contenidos individuales, entre otros, ha generado una sobreabundancia de expresiones sociales, memorias e identidades.

Ahora bien, la lectura digital, o más bien, navegar en Internet, se ha convertido en una de las vías de experiencia de interpretación e intercambio inmediato de información e impresiones sobre el mundo. Por lo que hoy más que nunca, la información cumple un papel central en las relaciones que se entretejen en los actos comunicativos, íntimamente ligados al lenguaje, no porque antes no fuese así, sino porque ahora buscar, filtrar y seleccionar información en Internet hace parte de las competencias básicas de la nueva alfabetización social que, desde la óptica de la sociedad de la información, prefiguran una visión del mundo y del hombre más allá de su subjetividad y corporalidad.

Esta información digitalizada o nacida digital, ambas consecuencias de las acciones, los sentimientos, las reflexiones o los intercambios de ideas del hombre, son el registro pleno de la memoria colectiva y social de la modernidad líquida, por lo que acceder a las informaciones y memorias será crucial y determinante para la dignificación y pleno reconocimiento de otros contenidos culturales, de otras memorias y otros discursos. Desde los documentos iconográficos y figurativos (planos, mapas, grabados, dibujos,) como audiovisuales (fotografías, diapositivas, postales, audios, podcast, videos, películas) e impresos (bandos, circulares, prensa y revistas).

Aunque las posibilidades de lo real se amplían, para muchos autores se trata de simulaciones, y no hay mejor ejemplo de ello que las redes sociales, en las que circulan las nuevas informaciones, que son por su parte un testimonio del pasado de la modernidad líquida, al proporcionar un marco comprensivo para las nuevas narrativas y discursos, de la "aldea global" que propuso McLuhan, en 1991, donde señala lo determinante que sería la información en la sociedad contemporánea, por su papel estratégico como elemento de desarrollo y control, esencial en el pensamiento cibernético y en las premisas sobre la biopolítica y el biopoder que propuso Foucault en su momento, y actualmente en el pensamiento posthumanista o transhumanista.

Información, cibernética y biopolítica, igual que globalización, son términos claves para la comprensión de las actuales relaciones, no solo entre Estado y nación, sino también para las relaciones que se dan entre la inclusión y la exclusión social, el hombre y la máquina y, en general, las relaciones entre la vida y la muerte. La tecnología ha de crear puentes para que estas relaciones sean cada vez más visibles dentro del panorama de control social.

Por último, las lenguas, las culturas y, en general el conocimiento, tienen por su parte, un efecto homogeneizador que se le atribuye a la globalización, y que subyace en la pérdida cultural de otras lenguas. Por lo que habría que considerar como urgente, la inclusión de informaciones en otros idiomas, dentro de las prácticas de transmisión de saberes, con el fin de garantizar mejores condiciones de acceso a la información a las poblaciones con menos recursos que es, por mucho, esencial para garantizar otras expresiones del pensamiento y otros discursos, así como otros sistemas de valores culturales que sirven para distinguir a los pueblos en su diversidad. Se debe, por lo tanto, como lo menciona Heddy Hidalgo Rivero (2014), entender la globalización también en términos lingüísticos de pluralidad, universalidad e intercambio cultural, especialmente en lo concerniente a las tecnologías del lenguaje y a su empleo para la difusión inmediata del conocimiento. 


\section{Q Referencias bibliográficas}

» Bauman, Zygmunt. 2017. La globalización. Consecuencias humanas. México: Fondo de Cultura Económica.

"Becerra, Martín. 2003. Sociedad de la información: proyecto, convergencia, divergencia. Buenos Aires: Editorial Norma, 156 p.

» Bertalanffy, Ludwig von. 1986. [1968]. Teoría General de los Sistemas: fundamentos, desarrollo, aplicaciones. México: Fondo de Cultura Económica.

»Bostrom, Nick. 2003. Human Genetic Enhancements: A Transhumanist Perspective. En Journal of Value Inquiry. Vol. 37, no. 4, 493-506. <http://cyber.law.harvard.edu/cyberlaw2005/sites/cyberlaw2005/images/Transhumanist_Perspective.pdf> [Consulta: 29 noviembre 2020].

» Bradbury, Ray. 1958. [1953]. Fahrenheit 451. Traducción de Francisco Abelenda. Buenos Aires: Minotauro.

»Breton, Philippe. 200o. La utopía de la comunicación: el mito de la aldea global. Buenos Aires: Nueva Visión.

"Brunori. Eliana. 2012. Un mundo feliz y Oryx y Crake: ¿un futuro posthumano? una mirada hacia las implicancias del desarrollo científico. En Forma. Revista d'humanitats. No. 6, 24-32. <https://www.raco.cat/index.php/Forma/article/ view/261154> [Consulta: 29 noviembre 2020].

» Bush, Vannevar. 1945. As We May Think. En The Atlantic Monthly, July.

"Dawkins, Richard. 1976. El gen egoísta. Las bases biológicas de nuestra conducta. Reino Unido: Oxford University Press.

»Derrida, Jacques. 1995. Mal de archivo. París: Éditions Galilée.

»Elías, Norbert. 2016. [1939]. El proceso de la civilización. Investigaciones sociogenéticas y sicogenéticas. México: Fondo de Cultura Económica.

»Foucault, Michel. 2004. Naissance de la biopolitique: Cours au Collège de France (1978-1979). Paris: Gallimard; Seuil.

» Gadamer, Hans. George. 1996. Verdad y Método I. Salamanca: Sígueme.

" González Quirós, José Luis. 1981. Las utopías negativas del siglo XX. El reformismo como utopía. En García Cotarelo, Ramón, ed. Las utopías del siglo XX. Madrid: Universidad Internacional Menéndez Pelayo. p. 97-114.

» Haraway, Donna. 1991. Manifiesto para Cyborgs: ciencia, tecnología y feminismo socialista a finales del siglo XX. <https://www.icesi.edu.co/blogs/antro_conocimiento/files/2012/o2/Haraway_MANIFIESTO-CYBORG.pdf> [Consulta: 29 noviembre 2020].

"Hayles, Katherine. 1999. How We Became Posthuman: Virtual Bodies in Cybernetics, Literature, and Informatics. Chicago: The University Chicago Press.

» Hidalgo Rivero, Heddy. 2014. Globalización, lenguaje y capitalismo cognitivo. En Observatorio Laboral Revista Venezolana. Vol. 7, no. 14, 85-101. <http://servicio. bc.uc.edu.ve/faces/revista/lainet/index.htm > [Consulta: 29 noviembre 2020].

» Huxley, Aldous. 1994. [1932]. Un mundo feliz. México: Editorial Porrúa. 
» Juanola Hospital, Eduard. 2004. Globalización y Cultura. Análisis crítico de los vínculos, efectos e interconectividad entre dos nociones. En Athenea Digital. Revista de pensamiento e investigación social. No. 6. <https://atheneadigital.net/ article/view/n6-juanola/171-html-es > [Consulta: 29 noviembre 2020].

»London, Jack. 1908. The Iron Heel. Londres: Macmillan Publishers.

"López Yepes, José. 1998. Hombre y documento: del homo sapiens al homo documentator. En Scire. Representación y organización del conocimiento. Vol. 4, no. 2, 11-22. <https://www.ibersid.eu/ojs/index.php/scire/article/view/1094 > [Consulta: 29 noviembre 2020$]$.

" López Yepes, José. 2008. Notas acerca del concepto y evolución del documento contemporáneo. En VII Jornadas Científicas sobre Documentación Contemporánea. Madrid: Departamento de Ciencias y técnicas historiográficas, UCM. p. 273-279. < http://www.ucm.es/centros/cont/descargas/documento11910.pdf > [Consulta: 29 noviembre 2020].

»Martín-Barbero, Jesús. 2002. La educación desde la comunicación. México: Norma.

" Melo Flórez, Jairo Antonio. 2011. Historia digital: la memoria en el archivo infinito. En Historia Crítica. No. 43, 82-103. <https://doi.org/10.7440/histcrit43.2011.06 > [Consulta: 29 noviembre 2020].

"McLuhan, Marshall y Bruce R. Powers. 1991. La aldea global: transformaciones en la vida y los medios de comunicación mundiales en el siglo XXI. México: Gedisa.

»Morales Campos, Estela. 2007. El multiculturalismo, la sociedad globalizada y la biblioteca. En Morales Campos, Estela, coord. El multiculturalismo y los servicios de información. México: UNAM, Centro Universitario de Investigaciones Bibliotecológicas. p. 53-68. <http://ru.iibi.unam.mx/jspui/handle/IIBI_UNAM/ CL912> [Consulta: 29 noviembre 2020].

» Noriega, Luis. 2011. Iménez. Bogotá: Taller de edición Roca.

》 Ortiz, Renato. 2009. La supremacía del inglés. En Revista cTPcba. No. 98, 50. <http:// www.bibliotecact.com.ar/PDF/03198.pdf> [Consulta: 29 noviembre 2020].

»Ortiz Palacios, Jimmy. 2016. Algunas notas al margen para una investigación por trazar: dimensión tecnológica del poder. En Revista Filosofía UIS. Vol. 15, no. 1, 213-223 <https://doi.org/10.18273/revfil.v15n1-2016001>

》 Orwell, George. 1948. 1984. Reino Unido: Secker \& Warburg.

"Paz Soldán, Edmundo. 2000. Sueños digitales. La Paz: Alfaguara.

»Paz Soldán, Edmundo. 2003. El delirio de Turing. Madrid: Alfaguara

» Pulido Cañabate, Estrella. 2016. Big Data: ¿solución o problema? En Encuentros multidisciplinarios. No. 53. <http://www.encuentros-multidisciplinares.org/ revista-53/estrella_pulido.pdf> [Consulta: 29 noviembre 2020].

"Saldías Rossel, Gabriel Alejandro. 2015. En el peor lugar posible: teoría de lo distópico y su presencia en la narrativa tardofranquista española (1965-1975). Barcelona: Universitat Autónoma de Barcelona. 519 p. Tesis de doctorado. <https:// tdx.cat/handle/10803/295707\#page=3> [Consulta: 29 noviembre 2020].

"Sartori, Giovanni. 1998. Homo videns. La Sociedad Teledirigida. Buenos Aires: Taurus. 
»Siles González, Ignacio. 2007. Cibernética y sociedad de la información: el retorno de un sueño eterno. En Signo y Pensamiento. Vol. 25, no. 50, 84-99. <https:// revistas.javeriana.edu.co/index.php/signoypensamiento/article/view/4615> [Consulta: 29 noviembre 2020].

»Silva Silva, Alicia. 2008. La globalización cultural y las tecnologías de información comunicación en la cibersociedad. En Razón y Palabra. No. 64. <http:// www.razonypalabra.org.mx/N/n64/varia/asilva.html> [Consulta: 29 noviembre 2020].

»Simón Ruiz, Cristina. 2010. Español actual: Globalización e interculturalidad. En Decires, Revista del Centro de Enseñanza para Extranjeros. Vol. 12, no. 14, 75-89.

"Szlejcher. Anna. 2008. La formación del archivero y la preservación de la autenticidad del patrimonio digital. En Revista del Archivo Nacional. No 72, no 1-12, 85108. <http://www.dgan.go.cr/ran/index.php/RAN/article/view/178> [Consulta: 29 noviembre 2020].

» Tejeda González, José Luis. 2011. Biopolítica, control y dominación. En Espiral. Estudios sobre Estado y Sociedad. Vol. 18, no. 52, 77-107. <http://www.espiral.cucsh. udg.mx/index.php/EEES/article/view/908> [Consulta: 29 noviembre 2020].

»Turkel, William. 2005-08. Digital history hacks: methodology for the infinite archive. [Weblog.] <http://digitalhistoryhacks.blogspot.com/> [Consulta: 29 noviembre 2020].

»Urbina Blanco, Samuel Alejandro. 2020. Psico-biopolítica, memes e intertextualidad en un mundo pospandémico. $<$ https://ssrn.com/abstract=3676449> [Consulta: 29 noviembre 2020].

»Villegas Iriarte, Édgar y Rocío Rueda Ortíz. 2017. Web social, viajeros y utopías digitales. En Nómadas. No. 47, 47-63. <DOI: 10.30578/nomadas.n47a2>

»Von Werder, Sophie. 2020. Mundos y seres poshumanos en la literatura contemporánea: Estudio comparado de Kafka, Borges, Santa Cruz, DeLillo y Bellatin. Medellín: Universidad de Antioquia.

»Wiener, Norbert. 1985. [1948]. Cibernética o el control y comunicación en animales y máquinas. Barcelona: Tusquets.

»Wolton, Dominique. 200o. Internet, ¿y después?: una teoría crítica de los nuevos medios de comunicación. Barcelona: Gedisa

» Zamiatin, Yevgueni. 1991. [1924]. Nosotros. Traducción de Margarita Estapé. Barcelona: Tusquets. 